\title{
Comparative analysis of two CBN grinding wheels performance in nodular cast iron plunge grinding
}

\author{
Lucas de Martini Fernandes ${ }^{1}$ - José Claudio Lopes ${ }^{1} \cdot$ Roberta Silveira Volpato $^{1}$ • Anselmo Eduardo Diniz ${ }^{1}$. \\ Rodolfo Fischer Moreira de Oliveira ${ }^{2} \cdot$ Paulo Roberto de Aguiar $^{1} \cdot$ Hamilton José de Mello $^{1} \cdot$ Eduardo Carlos Bianchi $^{1}$ (D)
}

Received: 8 January 2018 / Accepted: 7 May 2018 / Published online: 9 June 2018

(C) Springer-Verlag London Ltd., part of Springer Nature 2018

\begin{abstract}
The extensive tribological use of nodular cast iron in ground transport industry, e.g., trains and automobiles, has brought growing scientific interest. The various applications of this material are due to the versatility of mechanical properties without adding alloy elements, making possible to achieve good results varying just the heat treatment. Due to its high fluidity, workpieces made of this material can be produced with final dimensions and shapes very close to the designed ones, making necessary just the use of finishing machining operations to get the final dimensions, more specifically those concerning the grinding process. To optimize cost production, machining processes became the focus of scientists and engineers. The grinding wheel can determine the success of an operation as its properties influence productivity and workpiece quality decisively. This work analyzes the grinding process of the ductile iron GGG-70 (average hardness of $270 \mathrm{HB}$ ) using two types of vitrified bonded CBN grinding wheels, which have as their only distinction the marked difference in friability of the abrasive grains. The performance of each grinding wheel will be analyzed taking into account the output parameters values obtained from surface roughness, average power, diametric wear of the grinding wheel, microstructure of the ground surfaces, and microhardness measures from the ground surface to the center of the workpiece. It was observed that the less friable wheel produced, regarding the average surface roughness, values of $0.27,0.30$, and $0.36 \mu \mathrm{m}$ for the feed rates of $0.5,1.0$, and $1.5 \mathrm{~mm} / \mathrm{min}$, respectively, and, regarding the diametric wheel wear, produced values of 2.52, 2.99, and $4.01 \mu \mathrm{m}$ for the same feed rates, respectively. On the other hand, when using the more friable wheel, average surface roughness values of $0.33,0.44$, and $0.64 \mu \mathrm{m}$ and diametric wheel wear values of $3.21,4.22$, and $7.24 \mu \mathrm{m}$ were obtained. In this way, the less friable wheel showed better results for all the conditions. Considering the feed rate order of $0.5,1.0$, and $1.5 \mathrm{~mm} / \mathrm{min}$, the improvement in surface roughness was about 18.18,31.82, and $43.75 \%$, respectively, and the reduction of the wheel wear was about $21.50,29.15$, and $44.61 \%$.
\end{abstract}

Keywords Cylindrical grinding $\cdot$ Friability $\cdot \mathrm{CBN} \cdot$ Nodular cast iron

Lucas de Martini Fernandes

lucas-asewas@hotmail.com

José Claudio Lopes

jclaudio.lopes@hotmail.com

Roberta Silveira Volpato

roberta_sv@hotmail.com

Anselmo Eduardo Diniz

anselmo@fem.unicamp.br

Rodolfo Fischer Moreira de Oliveira

rodolfo.oliveira@saint-gobain.com
Paulo Roberto de Aguiar aguiarpr@feb.unesp.br

Hamilton José de Mello hamilton@feb.unesp.br

Eduardo Carlos Bianchi bianchi@feb.unesp.br

UNESP, Bauru, Brazil

2 Saint-Gobain Surface Conditioning - Ceramic Materials, Guarulhos, Brazil 


\section{Introduction}

Grinding is the recommended machining process to meet the requirements of high surface, dimensional, and geometric quality. It is therefore usually the last process in a sequence of machining operations and the workpiece already has a high added value when it reaches this stage, making its rejection very expensive.

With the goal of keeping the competitiveness in global markets, the cost of production must be kept low. At the same time, the variety of products is increasing fast, while the life cycles of products shorten. With that, the competitiveness of manufacturing companies depends on their capacity to adapt to the rapid changes in global conditions [1].

This paper presents a comparative analysis of the performance of two CBN grinding wheels with the same specifications in the grinding of GGG-70 nodular cast iron at different infeed rates, highlighting their advantages and disadvantages based on the results obtained. The difference between the tools is the friability level of the abrasive grains, which gives each one its distinct characteristics and properties.

The success of a grinding operation is largely determined by the right choice of grinding wheel. The properties of the grinding wheel affect productivity and workpiece quality, taking into account the process parameters and the workpiece material [2]. In this way, a study to determine the effect of the friability level on the process is very important.

It is known that increasing infeed rate, with other speeds constant, increases grinding forces and roughness and reduces specific energy. Therefore, the process becomes more energy efficient up to the point that the high infeed rate leads to high wheel wear and low grinding ratio (G-ratio) [3].

Friability refers to the tendency of a grain to fracture under compression. More friable grains are better for low grinding forces. Grain fracture produces sharp new edges; hence, friability is an advantage for maintaining grinding wheel sharpness. Friable abrasives tend to cause the wheel to wear more rapidly than less friable ones, which can be advantageous in the grinding of some materials and in some operations [3].

Producers can choose the most adequate among many different levels of friability of the abrasive grains in one single type of grinding wheel. Low friability does not necessarily ensure long grain service life. Grains with very low friability for a given application become dull and increase friction, thermally damaging the workpiece and causing unnecessary vibration. On the other hand, excessively friable grains wear down quickly, resulting in shorter tool life and possible shape errors. Ideally, the fracture behavior of grinding wheel grains should be controlled so the sharp cutting edges are regenerated and the tool works in self-sharpening mode [4].

Novoselov et al. (2016) carried out a kinematic analysis of abrasive grain wear process. It was stated that the wear of abrasive grain occurs in the contact zone, which increases as the wheel penetrates the workpiece. In external cylindrical grinding, it represents geometrically the form of two segments (Fig. 1). The real contour of the contact zone, however, is different from its geometric representation because, when the abrasive grains come in contact with the workpiece material, the radius $r$ of the workpiece decreases on the value of the radial material removal $\Delta r$, the radius of the grinding wheel $R$ decreases on the value of its radial wear $\Delta R$, and the roughness layer remains on the surface [5].

Also, the abrasive grains on the wheel working surface are located at different depths from the outer surface of the tool and their operation depends on the length of the motion trajectories in the contact zone and the contact conditions with the workpiece material. Before entering a contact zone, the surface has a certain microrelief which was formed on a previous operation or during current grinding process. In grinding, a single grain, passing the contact zone, can cut material if it touches a roughness peak of the workpiece surface or not cut if it reaches a valley. When the grain meets roughness peak, the amount of removed material increases. When it reaches a valley, it does not remove material, but the probability of a subsequent contact increases [5].

In his work, Jackson [6] concludes that, for vitrified CBN grinding wheels, the dominant cause of abrasive material loss during a grinding operation is bond and grain fractures.

The wear mechanism of a grinding wheel can be basically divided in three grain/bond breakdown modes: total breakout, macro-fracture, and micro-fracture (Fig. 2). Ideally, the abrasive grain should fracture creating the loss of relatively fine particles typically at the micron or sub-micron level, a process known as "micro-fracturing." The remaining portion of the grain should remain sharp and capable of cutting. If the grain is too tough relative to the bond holding it, or the grinding force/grain is extremely high, then the grain can go through total break-out or loss without doing any useful work. If the bond is strong enough to hold the grain but there are high grinding forces/grain, and/or the grain crystallite size is

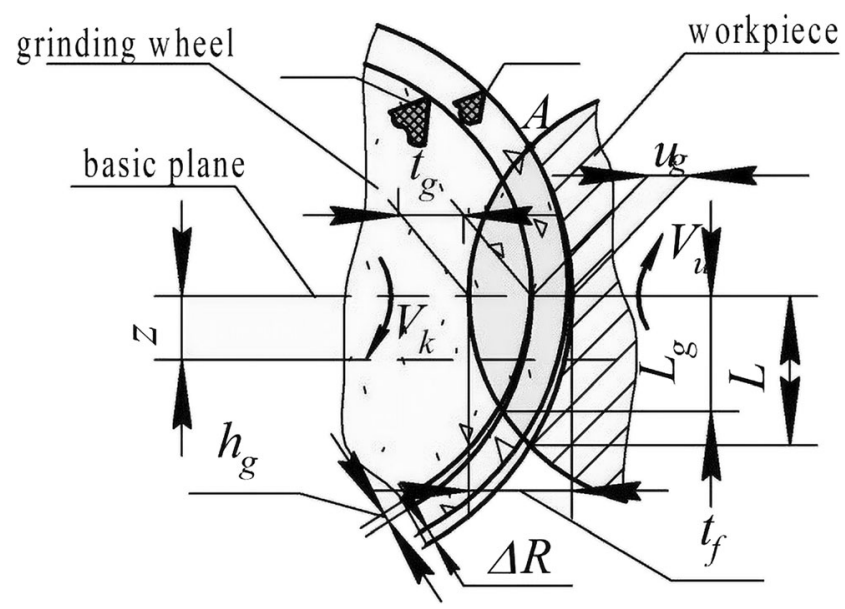

Fig. 1 Scheme for calculation of cutting path by single abrasive grains [5] 
Fig. 2 Grain/bond breakdown modes in grinding wheels [7]

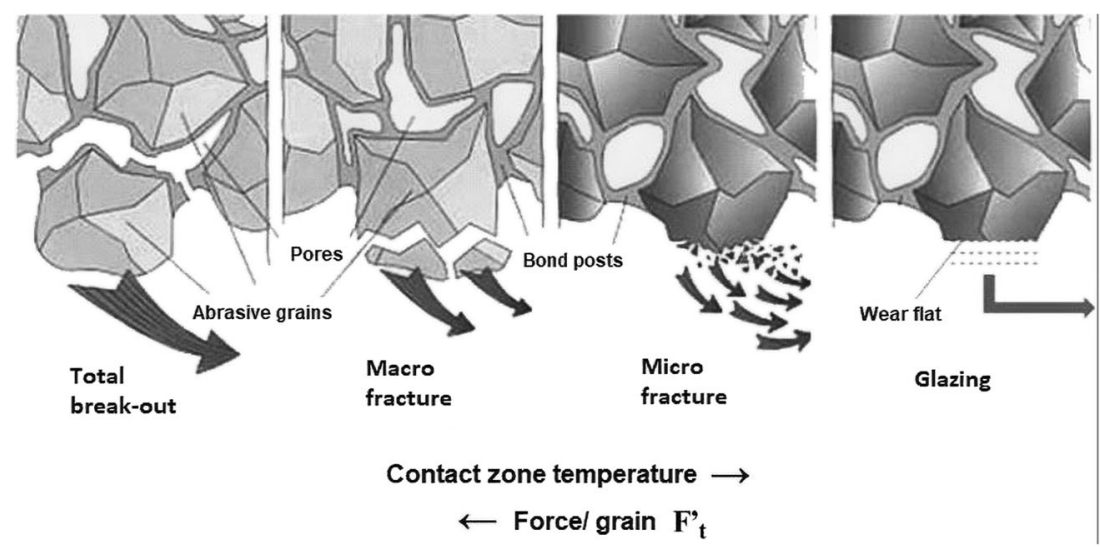

large, then the predominant fracture mode is a coarse loss of grain by "macro-fracturing" still without the full amount of possible useful work. On the other hand, if the grain is much weaker than the bond and/or prone to high attritious wear due to mechanical, heat, or chemical wear, then "glazing" occurs resulting in the creation of wear flats, high grinding forces and increased interface temperature. Higher forces stimulate in order more fracture [7].

Higher friability increases the frequency and level of fracture of the abrasive grains. In this way, in a more friable grinding wheel, there are more cutting edges which make the material removal easier, resulting in lower forces on the process and the lower probability of total break-out or glazing of the grains.

Also, Ding et al. [8] studied and related some investigations on the literature which explored that grain wear caused by macro-fracture at the grain-bond junction reduces the wheel life significantly and should be minimized. On the other hand, micro-fracture in the vertex region of a grain can enhance the sharpness of a grinding wheel.

Another very important parameter to evaluate the performance of the grinding wheel is the surface roughness, which also is the most important evaluation indicator to assess ground surface quality. In grinding, surface roughness is usually difficult to be predicted due to the random distribution of abrasive grits and various material properties. However, the ability to precisely predict it could be very helpful to reduce the cost and improve productivity. The factors that affect the surface quality are not only the grinding wheel topology, workpiece, lubrication conditions, and operation parameters but also the nature of materials itself [9]. The material chosen for this research was nodular cast iron, which was introduced into the market long ago, but has been under continuous development in recent decades. This has broadened its scope of applications, leading to a significant growth in the global production rates of this material in recent times [10].

Nodular cast iron is also used in the production of a variety of parts in which mechanical requirements and reliability are crucial attributes. Some examples are crankshafts, suspension parts, several industrial machine parts, gears, piston sleeves, camshafts, valves, and pumps, among several other components, due to its excellent combination of high ductility, high strength, low wear, and relatively low production costs [9-12]. The machining costs involved in the manufacture of nodular cast iron crankshafts are up to $50 \%$ lower than those of forged steel crankshafts, which is one of the main reasons why most companies use nodular cast iron instead of steel for this kind of part.

In comparison to the efforts required to grind hardened steel, the mechanical and thermal stresses are lower when grinding nodular cast iron. Also, in comparison to steel, cast iron materials are considered brittle. Brittle materials deform elastically up to the elastic limit and then shear with very little plastic flow. In contrast, ductile materials yield and may harden while undergoing substantial plastic flow, allowing plastic deformation many times larger than the elastic strain. The motive why the behavior is different is that in brittle materials, crack growth predominates over plastic flow as the yield mechanism. In many engineering materials, yield takes place by a combination of plastic flow and crack propagation [3].

A material that exhibits a high yield stress and large plastic strain before failure is said to be tough. A material that fails at low values of fracture stress and exhibits little strain is said to be lacking in toughness. In this way, materials such as cast iron require less energy for material removal than the tougher crankshaft steel for instance. As toughness increases, grinding energy is also increased [3].

Such is the importance of nodular cast iron that its production takes $40 \%$ of the cast iron market [13]. However, most of the components made with nodular cast iron cannot be used as they come out of the casting process and must be machined in order to have a good component quality. Because of that, it is very important to evaluate the performance of the tools used in the machining of nodular cast iron [14].

In view of the broadened scope of applications of the nodular cast iron and the extensive use in precision components in which high quality of the components is necessary in order to achieve the lowest possible cost, an analysis of the effect of 
each property of the grinding wheel in the efficiency of the process is essential. In this way, since there are very few studies regarding the effect of this property alone on a material that is very frequently used in industry, it is important to have a better understanding of this parameter to employ the best tool to either reduce costs or improve the workpiece quality.

\section{Experimental setup}

The tests were performed on a CNC cylindrical grinding, model RUAP $515 \mathrm{H}$, made by SULMECÂNICA. The grinding wheels used were vitrified bonded CBN wheels specified as SNB151.GS Q12 VR2 and SNB151.GL Q12 VR2. The difference between these two wheels is just the noticeable variation of friability between both grains, so that the GS wheel is the most friable one and the GL wheel is the less friable one (Fig. 3).

The grinding wheels were made with the following dimensions: $350 \mathrm{~mm}$ (outside diameter) $\times 19 \mathrm{~mm}$ (thickness) $\times$ $127 \mathrm{~mm}$ (hole diameter). The geometry and dimensions can be seen in Fig. 4.

The workpieces were made of GGG-70 nodular cast iron with average Brinell hardness (HB) of 270 and were ring shaped, with an external diameter of $92 \pm 0.1 \mathrm{~mm}$, internal diameter of $30 \pm 0.1 \mathrm{~mm}$, and thickness of $5 \pm 0.1 \mathrm{~mm}$.

During the tests, $28 \mathrm{~mm}$ of material was removed from the external diameter of the ring ( 280 grinding cycles with $100 \mu \mathrm{m}$ of material removed per pass), resulting in an external diameter of $64 \pm 0.1 \mathrm{~mm}$. The wheels were dressed using a multi-granular agglomerate dressing tool, from Master Diamond. The cutting fluid used was a semi-synthetic soluble cutting oil with concentration of 2.5\% (QUIMATIC ME-I) and all the tests were performed using abundant fluid.

The mechanical properties of the ductile iron, according to DIN 1693 are shown in Table 1.

The chemical composition of the workpiece material was analyzed using an optical emission spectrometer type GNR Metal Lab 75-80J. The results are shown in Table 2.
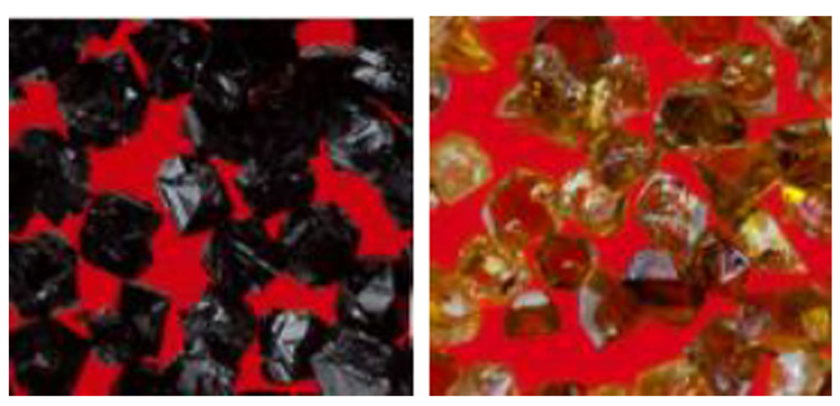

Fig. 3 Abrasive grains of the CBN GS grinding wheel (left) and CBN GL grinding wheel (right), names given by the manufacturer Nikkon Ferramentas de Corte Ltda
The tests were conducted under three infeed rates -0.5 , 1.0 , and $1.5 \mathrm{~mm} / \mathrm{min}$. In order to obtain greater statistic reliability, the procedures were done three times for each feed rate. Therefore, a total of 18 samples were studied ( 2 wheels, 3 infeed rates, and 3 replications of each experiment).

The output variables analyzed were surface roughness, grinding power, diametric wheel wear, optical microstructure of the machined surfaces, and the gradient of microhardness from the surface to the inner workpiece.

The remaining information can be found in Table 3:

Due to the great reduction of the external diameter of the ring (28 $\mathrm{mm}$ of reduction for each experiment), the peripherical speed of the workpiece was substantially reduced from 0.39 to $0.27 \mathrm{~m} / \mathrm{s}$. This reduction considerably affected the system and output parameters, but being constant in every condition, it did not cause any interference in the comparative analysis.

The cutting speed of $32 \mathrm{~m} / \mathrm{s}$ was chosen due to the limitation of the system. However, in combination with the workpiece peripherical speed, it allowed the comparative analysis of the performance of the grinding wheels at a finishing condition. The grinding process is said to be in finishing condition when the cutting/workpiece peripherical speed ratio is between 90 and 120 as can be seen in Eq. (1):

$q_{\mathrm{s}}=\frac{V_{\mathrm{s}}}{V_{\mathrm{w}}}=\frac{n_{\mathrm{s}} \times d_{\mathrm{s}}}{n_{\mathrm{w}} \times d_{\mathrm{w}}}$

$n_{\mathrm{S}}$ is the rotational speed of the grinding wheel; $n_{\mathrm{w}}$ is the rotational speed of the workpiece and $d_{\mathrm{s}}$ and $d_{\mathrm{w}}$ are the grinding wheel and workpiece diameters, respectively.

Considering the available rotational speed values of the system, the best option would be $81 \mathrm{rpm}$ for $n_{\mathrm{w}}$ aiming to obtain a $n_{\mathrm{s}}$ ratio of approximately 120 , since the lower the workpiece peripherical speed, the higher the ratio. In this way, it was calculated that removing $28 \mathrm{~mm}$ of material from the external diameter of the workpiece would provide a value in the range for finishing condition.

Also, regarding the spark-out time, it is recommended in literature the use of a time between 10 and 20 rotations of the workpiece. Since the time for 10 rotations is $7.4 \mathrm{~s}$. Therefore, $8 \mathrm{~s}$ was chosen as spark-out time, which is equivalent to approximately 11 rotations of the workpiece.

The dressing depth of $80 \mu \mathrm{m}$ was obtained experimentally to allow the complete homogenization of the grinding wheel surface and recovery of the condition before machining.

\subsection{Data acquisition}

In this study, the emphasis during data acquisition was on power-related data, which was collected by means of a power module containing two Hall effect sensors, one for current and other for voltage measurements. This procedure enables data 
Fig. 4 Grinding wheels geometry and dimensions

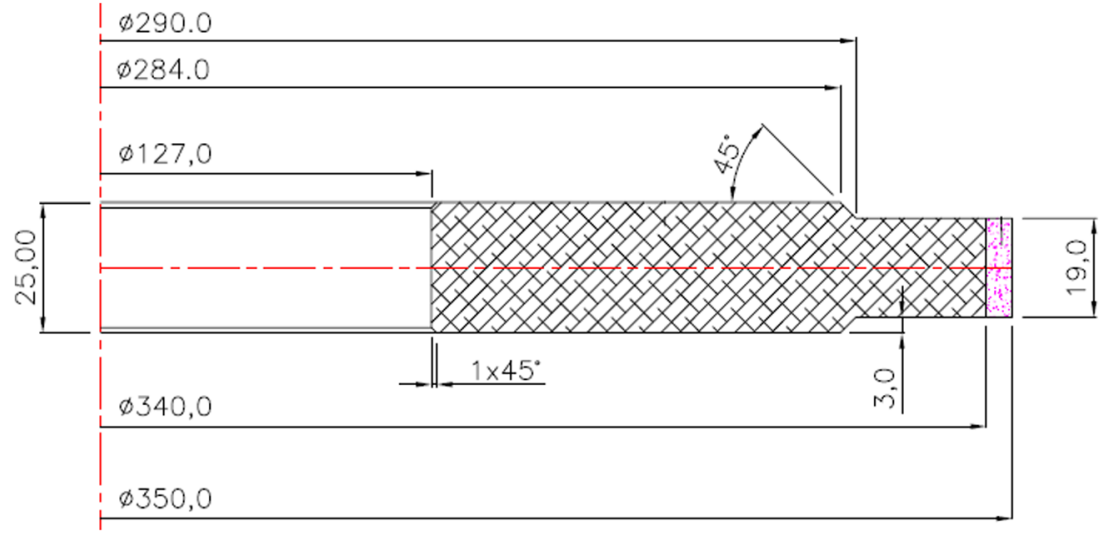

to be acquired in real time during the grinding process. The signals obtained in these sensors were multiplied by an integrated circuit, resulting in the instantaneous power. A computer equipped with an A/D data acquisition board and LabVIEW 7.1 software was used along with the power module. The data collected in real time was simultaneously recorded in the computer in the form of voltage (V), which was then converted into watts (W) by proper mathematical manipulation on MATLAB software.

\subsection{Parameters measurements}

The average roughness was obtained from measurements taken with a Surtronic 3+ roughness gage, from Taylor-Hobson, with gauge movement in the ring axial direction, using a cutoff length of $0.25 \mathrm{~mm}$ and a total path $\left(l_{\mathrm{n}}\right)$ of $1.25 \mathrm{~mm}$.

The same device was used to measure the grinding wheel's diametric wear. The method consisted in grinding a cylinder, removing a certain volume of material. With that, the existing unevenness between the worn and non-worn surfaces of the wheel was transfered to the cylinder, which was subsequently measured.

Since there was wheel wear on the machined zone with consequent reduction in its diameter in relation to the nonmachined zone, the cylinder in which was printed the grinding wheel profile presented larger diameter on the worn zones of the wheel and smaller diameter on the zones that the wheel did not touch the workpiece. With that, the printing of the worn wheel profile was made on a SAE 1020 steel cylinder (Fig. 5) after every two tests (each workpiece was ground on regions properly spaced apart so that the worn regions would not influence each other).

After this procedure, the wheel profile of wear was generated using the Taylor-Hobson TalyMap software and measured with the roughness gage, which was programmed to pass longitudinally over $4 \mathrm{~mm}$ of the cylinder. This enabled the determination of the unevenness between the worn and non-worn regions, as seen in Fig. 6:

After obtaining the profile, a software tool was used to measure the difference in depth between two points generated in the profile to acquire the value of the diametric wheel wear. To obtain a more accurate value, average points of each region were used.

The equipment was often calibrated using a standard workpiece with known surface roughness.

For the tool wear, the total path $\left(l_{\mathrm{n}}\right)$ used was $4 \mathrm{~mm}$, the cutoff wavelength $\left(l_{\mathrm{C}}\right)$ was $0.8 \mathrm{~mm}$, and the chosen parameters on the equipment were surface roughness $\left(R_{\mathrm{a}}\right)$ and G-ratio ().

The optical microscope used to obtain the micrographs was the Olympus BX51M, along with the analysis software for visualization and recording of the images. Through the images collected from the machined surface along with the microhardness analysis, it was possible to determine if thermal damage occurred during grinding.

For the microhardness analysis, a Buehler microhardness tester, model 1600-6300, was used, using the Knoop method
Table 1 Mechanical properties of ductile iron (DIN 1693)

\begin{tabular}{lllll}
\hline Grade & $\begin{array}{l}\text { Material No. } \\
\text { W-Nr. }\end{array}$ & $\begin{array}{l}\text { Tensile } \\
\text { strength } \\
\sigma_{\mathrm{b}} \geq(\mathrm{Mpa})\end{array}$ & $\begin{array}{l}\text { Yield } \\
\text { strength } \\
\sigma_{0.2} \geq(\mathrm{Mpa})\end{array}$ & $\begin{array}{l}\text { Elongation } \\
\delta \geq(\%)\end{array}$ \\
\hline GGG-40 & 0.7040 & 400 & 250 & 15 \\
GGG-50 & 0.7050 & 500 & 320 & 7 \\
GGG-60 & 0.7060 & 600 & 380 & 3 \\
GGG-70 & 0.7070 & 700 & 400 & 2 \\
GGG-80 & 0.7080 & 800 & 500 & 2 \\
\hline
\end{tabular}


Table 2 Chemical composition of the workpiece material

\begin{tabular}{llll}
\hline $\mathrm{C}$ & $3.65 \%$ & $\mathrm{P}$ & $0.05 \%$ \\
$\mathrm{Mn}$ & $0.30 \%$ & $\mathrm{Mg}$ & $0.045 \%$ \\
$\mathrm{Si}$ & $2.25 \%$ & $\mathrm{Cu}$ & $0.80 \%$ \\
$\mathrm{~S}$ & $0.013 \%$ & $\mathrm{Mo}$ & $0.080 \%$ \\
\hline
\end{tabular}

of indentation. The indentations were made so that they obeyed the ASTM E92-16 regulation, respecting the minimum distance of 2.5 times the diagonal made by the indenter against the surface. The indentations were made in a way they did not interfere with one another and on different columns so that microhardness values of points in different distances could be obtained. This analysis was made to observe if any alteration in the microhardness values occurred caused by the grinding process on the workpiece surface and subsurface, which would be indicated by a gradient of values from the surface to the center of the workpiece in case of any thermal damage occurrence.

\section{Results}

The results obtained will be presented with comparative graphs to allow a good visualization of the difference of the results obtained with each grinding wheel.

\subsection{Diametric wheel wear and G-ratio}

The average values obtained for the diametric wheel wear for each condition are shown in Fig. 7:

An analysis of Fig. 7 indicates that the diametric wear of the CBN GL grinding wheel was considerably lower than that of the CBN GS at all the feed rates. For the less friable tool, values of 2.52, 2.99, and $4.01 \mu \mathrm{m}$ for the feed rates of $0.5,1.0$, and $1.5 \mathrm{~mm} / \mathrm{min}$, respectively, were obtained. CBN GS wheel, on the other hand, produced values of $3.21,4.22$, and

Table 3 Data of the used experimental conditions

\begin{tabular}{ll}
\hline Experimental conditions & Values \\
\hline Feed rate $\left(v_{\mathrm{f}}\right)$ & $0.5,1.0,1.5 \mathrm{~mm} / \mathrm{min}$ \\
Workpiece peripheral speed $\left(v_{\mathrm{w}}\right)$ & $0.39 \mathrm{~m} / \mathrm{s}$ (initial) \\
& $0.27 \mathrm{~m} / \mathrm{s}$ (final) \\
Cutting speed $\left(v_{\mathrm{s}}\right)$ & $32 \mathrm{~m} / \mathrm{s}$ \\
Spark-out time & $8 \mathrm{~s}$ \\
Dressing depth & $80 \mu \mathrm{m}(2 \mu \mathrm{m} / \mathrm{pass})$ \\
Cutting depth $(a)$ & $0.1 \mathrm{~mm}$ \\
Grinding width $(b)$ & $5 \mathrm{~mm}$ \\
Cutting fluid flow rate & $17 \mathrm{~L} / \mathrm{min}$ \\
\hline
\end{tabular}

$7.24 \mu \mathrm{m}$. In this way, when using the CBN GL wheel, the reduction of the wear was about $21.50,29.15$, and $44.61 \%$, respectively.

From this data, it is possible to calculate the G-ratio for each experiment. This parameter is commonly used to determine the tool's efficiency and is the most important one to quantitatively describe the behavior of a grinding wheel in terms of material removal rate and wear [15]. Based on a constant volume of removed material and workpiece thickness in all the tests, and considering the initial diameter of the wheel to be approximately $350 \mathrm{~mm}$, which is a reasonable approximation, the G-ratio can be calculated using Eq. (2):

$G=\frac{V_{\mathrm{w}}}{V_{\mathrm{s}}}=\frac{\frac{\left(\pi D_{\mathrm{w}}{ }^{2}-\pi d_{\mathrm{w}}{ }^{2}\right)}{4} \times t}{\frac{\left(\pi D_{\mathrm{r}}^{2}-\pi d_{\mathrm{r}}^{2}\right)}{4} \times t}=\frac{\left(92^{2}-64^{2}\right)}{\left(350^{2}-d_{\mathrm{r}}^{2}\right)}$

where $V_{\mathrm{w}}$ is the volume of material removed, $V_{\mathrm{s}}$ is the volume of wheel wear, $D_{\mathrm{w}}$ is the initial workpiece diameter, $d_{\mathrm{w}}$ is the final workpiece diameter, $D_{\mathrm{r}}$ is the initial wheel diameter, $d_{\mathrm{r}}$ is the final wheel diameter, and $t$ is the workpiece thickness. The value of the G-ratio for each condition can be obtained by substituting the value of $d_{\mathrm{r}}$ in the last term of the expression. These values are illustrated in Fig. 8.

An analysis of Fig. 8 reveals an interesting behavior regarding the G-ratios of the CBN GL and CBN GS grinding wheels. At a feed rate of $0.5 \mathrm{~mm} / \mathrm{min}$, the G-ratios differed by 526.2 ; at $1.0 \mathrm{~mm} / \mathrm{min}$, they differed by 608.283 ; and at $1.5 \mathrm{~mm} / \mathrm{min}$, they differed by 694.232 . This behavior indicates a growing difference between the G-ratios of the two wheels, i.e., the ratio decreased considerably at every $0.5 \mathrm{~mm} / \mathrm{min}$ of increase in feed rate. However, the CBN GL wheel showed 80 to 90 units greater difference in the values between wheels compared to the difference observed in the previous feed rate, i.e., the difference in G-ratios increased along with increasing feed rate. This indicates that the CBN GL wheel is even more suitable for conditions which require higher grinding forces in the analyzed range.

Regarding the predominant breakdown mode of the grinding wheels, according to the engineering of the abrasive grains, the predominant fracture mode of the CBN GL grains is the micro-fracture, and for the CBN GS abrasive grains, the predominant fracture mode is both macro- and micro-fracture.

In this way, the G-ratio is directly related to the friability of the grinding wheels. CBN GS wheel, which presented more occurrence of macro-fracturing, results in more wheel wear for the same amount of material removal because the loss of abrasive grains' material is considerably higher in this case. On the other hand, CBN GL wheel, presenting predominance of micro-fracturing, loses much less material of the abrasive grains. That is the reason why the G-ratio was higher on the CBN GL wheel and lower on the CBN GS. 
Fig. 5 Printing of the worn wheel profile

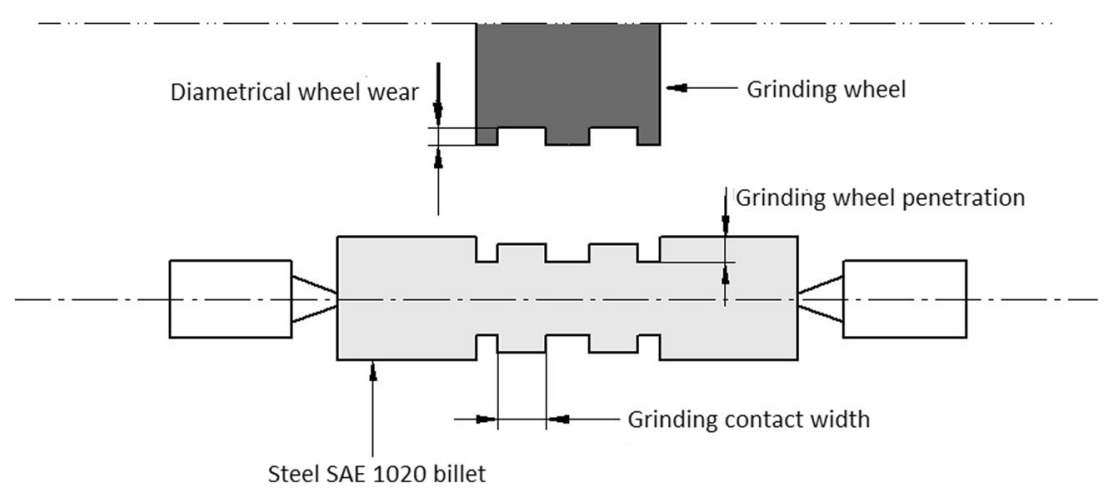

Also, it is important to observe that, at higher feed rates, the difference of both G-ratio and diametric wheel wear values between both wheels was accentuated. This occurs because when the most friable wheel is submitted to higher forces, macro-fracturing processes get even more accentuated and wear becomes even more expressive. The less friable wheel, on the other hand, could remove material more efficiently at the most severe condition $(1.5 \mathrm{~mm} / \mathrm{min})$, losing much less abrasive grains' material due to the predominance of microfracturing breakdown mode. In other words, with the tested grinding wheels, low friability indicates more occurrence of micro-fracturing and less wear, and very high friability indicates, especially at more severe conditions, predominance of macro-fracturing, resulting in accentuated wheel wear. Consequently, the G-ratio was found to be higher for the CBN GL wheel at the analyzedconditions and showed better performance.

Taborga [16] also analyzed in his research the G-ratio when the only variation was in the specific removal rate, which was controlled by means of a variation of the feed rate, seeing that, as in the present research, the cutting speed, workpiece speed, and grinding wheel's conditioning parameters were kept constant. The result obtained by the author was that with the increase of the specific removal rate, the diametric wheel wear also increased, and thus the G-ratio decreased. The explanation given by the authors for this phenomenon was that with an increase of specific removal rate there was also an increase in the cutting depth per wheel revolution and in the nondeformed chip thickness and, consequently, in the chip's momentane section, increasing the mechanical and thermal solicitations in grinding per grain, leading to an increase of diametric wheel wear.

Therefore, it is possible to say that the results obtained in this research for the variation of diametric wheel wear according to the variation in feed rate are coherent with the expected results.

Also, considering the removal of approximately $28 \mathrm{~mm}$ from the workpiece diameter, or, $17,153 \mathrm{~mm}^{3}$ of nodular cast iron at the selected parameters for a finishing condition and conventional lubri-refrigeration, the obtained values of diametric wheel wear, which reflected in G-ratio values between 862 and 2476, are within the expected when using a CBN grinding wheel and correspond to a range suitable to be used for real application in the production of components of the same material as the workpieces.

\subsection{Surface roughness}

The measurement of the workpiece surface roughness is one of the main points of the research, because not only it is an essential parameter in grinding - since, regardless of the component to be produced, small dimensional tolerances and high surface quality are usually dominant aspects of the process - it is also one of the parameters that allow the comparison of efficiency between the grinding wheels under different feed rates in the grinding of nodular cast iron.

Furthermore, the analysis of this parameter is extremely important, since it is well-known that the surface finish can significantly affect the resistance of the components when they undergo fatigue cycles. Moreover, the surface finish of
Fig. 6 Generated profile of the wheel on the cylinder, which allows the acquiring of the diametric wheel wear

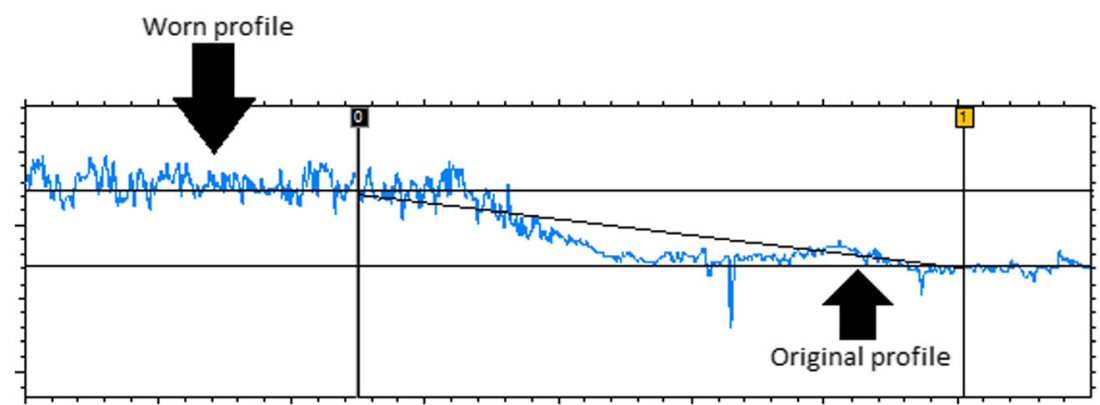




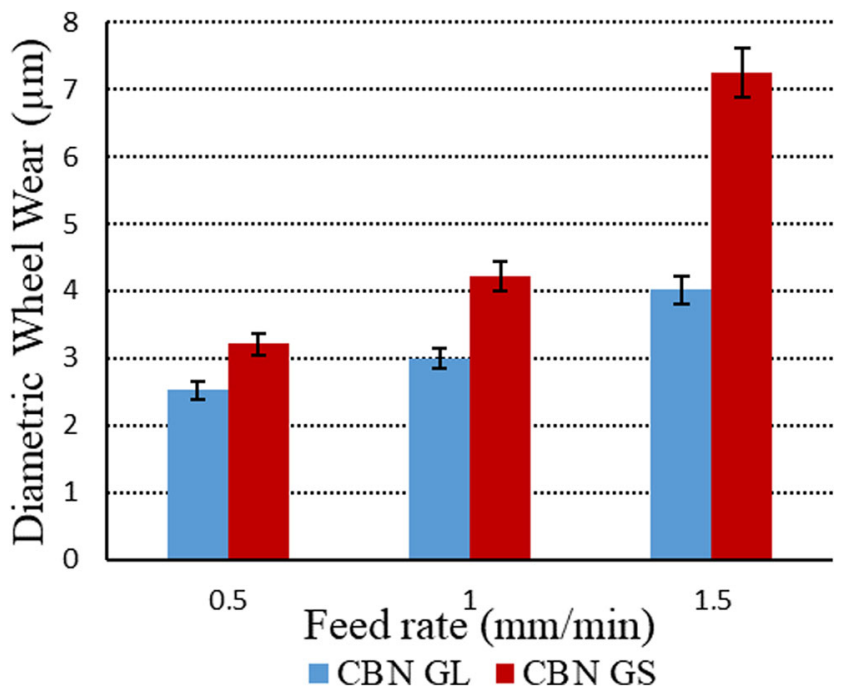

Fig. 7 Diametric wheel wear in each experimental condition

the workpiece is directly connected to some material's properties, such as friction coefficient, abrasion and lubrication capacity, thermal conductivity, mechanical resistance, and others [17]. A good example of a nodular cast iron component that undergoes grinding and fatigue cycles is the crankshaft of automobile engines.

After the data acquisition, it was possible to plot a graph comparing the average roughness values between the grinding wheels, as shown in Fig. 9:

Regarding the feed rate, it was observed that an increase of the feed rate resulted in higher values of surface roughness for both grinding wheels. This can be explained by the fact that higher feed rates result in higher values of equivalent chip thickness and material removal rates because of the increase in the penetration rate per revolution of the workpiece. An increase in equivalent chip thickness, in turn, causes increased stress on the abrasive grains and an increase in the material

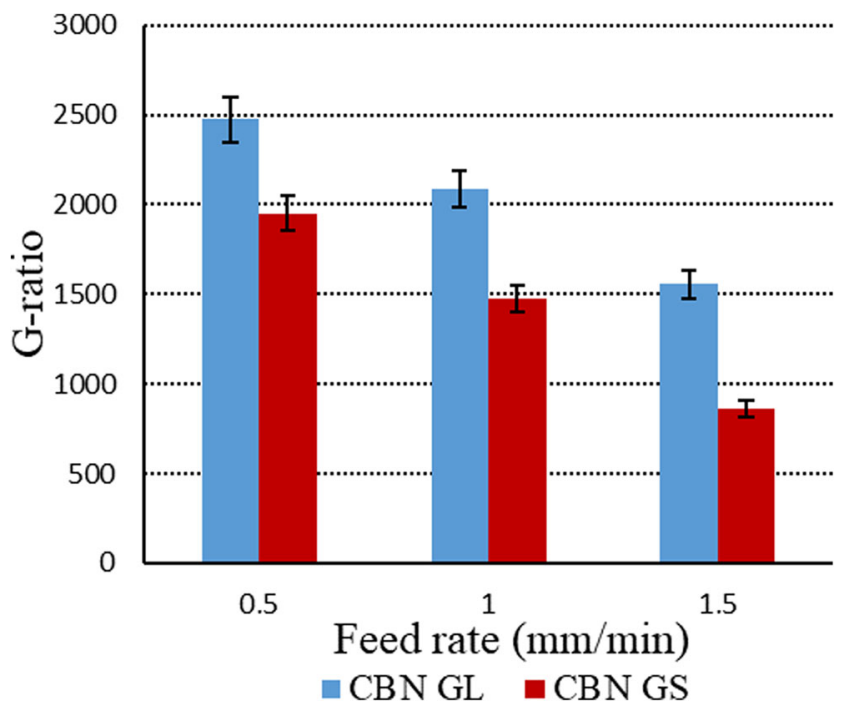

Fig. 8 Value of the G-ratio in each experimental condition

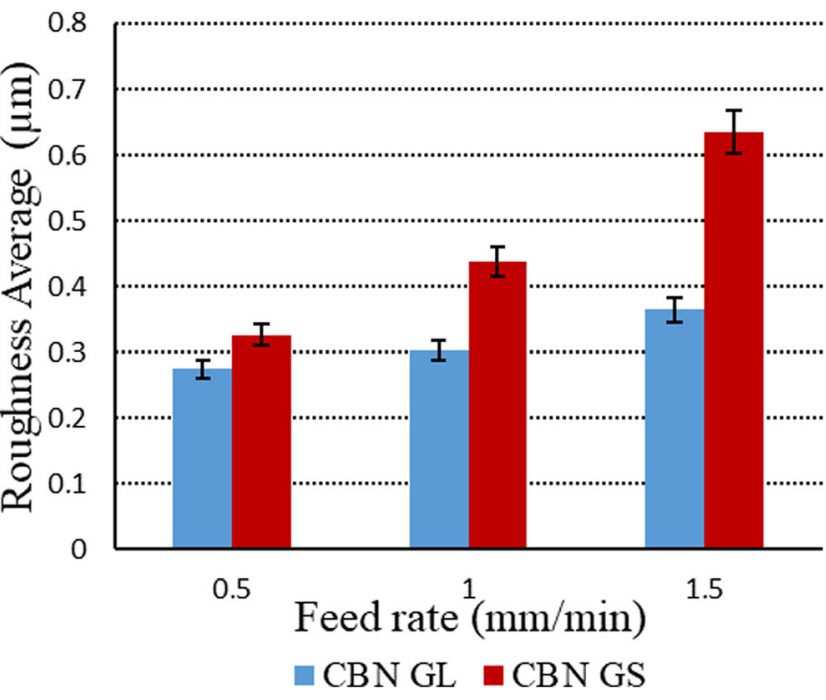

Fig. 9 Average surface roughness of the two grinding wheels resulting from each feed condition

removal rate implies longer wheel-workpiece contact, leading to directly proportional and higher cutting forces and power, meaning this parameter is highly pertinent to machine forces, deflections, and power consumption [3].

Since feed rate and grain friability were the only variables, it was found that, at the same feed rate, the surface roughness of the CBN GL grinding wheel was lower in all the experimental conditions. With this tool, values of $0.27,0.30$, and $0.36 \mu \mathrm{m}$ for the feed rates of $0.5,1.0$, and $1.5 \mathrm{~mm} / \mathrm{min}$, respectively, were obtained. On the other hand, with the CBN GS wheel, values of 2.52, 2.99, and $4.01 \mu \mathrm{m}$ for the same feed rates were obtained.The improvement in surface roughness when using the less friable wheel was about 18.18, 31.82 and $43.75 \%$, respectively.

Taborga et al. [18] did a similar analysis of surface roughness in function of the feed rate, but using silicon carbide and aluminum oxide grinding wheels. These authors obtained results similar to the one achieved in this research that with an increase in feed rate and a decrease in cutting speed, there is an increase in surface roughness. The authors' explanation for this phenomenon was that, when increasing the feed rate and, consequently, increasing non-deformed chip thickness due to the increase in feed per workpiece revolution, the surface roughness became higher.

It was also possible to notice a pattern in the differences in surface roughness between each wheel as the feed rate increased, in such a way that the difference in average surface roughness obtained for the samples of each wheel under the same condition was higher as the feed rate increased.

The reason for such difference in the results between the grinding wheels is deeply connected to the difference in grain friability. As said in Section 3.1, the predominant fracture mode of the abrasive grains of the CBN GL wheel is the micro-fracture, as it was designed for and the fracture mode 
of the abrasive grains of the CBN GS wheel is both macroand micro-fracture, also as it was engineered for.

The CBN GL wheel, having abrasive grains in which micro-fracture predominates during grinding, shows a lower total tool wear (as seen in Section 3.1), and thus a lower difference of abrasive grains protrusion from the wheel surface along its length and a more homogeneous cutting. Because of this characteristic, the CBN GL wheel can resist higher feed rates and cutting forces without showing high tool wear, being able to produce high quality and regular surfaces on the workpieces under the tested conditions. On the other hand, the CBN GS wheel, which also has considerable occurrence of macro-fracturing, showed higher tool wear which also resulted in a more accentuated difference of depths of the abrasive grains from the wheel surface along its length, resulting in a less homogeneous workpiece surface with the existence of more peaks and valleys, which means higher average surface roughness compared to the other wheel. Due to its high friability, as the feed rate increased, its wear also increased, since that under higher forces the occurrence of macro-fracturing is accentuated, resulting in a considerable increase in the average surface roughness.

In other words, as the feed rate increased, it is preferable to use a wheel with a grain in which micro-fracture predominates in order to obtain a better surface roughness. Regarding this parameter only, the CBN GS wheel works better in lower feed rates or under lower cutting forces. Regarding the CBN GL wheel, despite it showed an increase in surface roughness with the increase of feed rate, the difference in its values is not as high as in the other case, making this wheel a good candidate for operations that demand higher forces, due to the performance shown.

Considering that with the parameters used for a cylindrical grinding in a finishing condition and using conventional lubrirefrigeration, the required surface roughness for the components made of this material, such as automotive crankshafts, should be sometimes as low as $0.2 \mu \mathrm{m}$; the use of CBN GS wheel with feed rates of 1.0 and $1.5 \mathrm{~mm} / \mathrm{min}$ might not be suitable due to the obtainment of values higher than $0.4 \mu \mathrm{m}$. In this way, even with the use of the parameters for finishing condition, at more severe conditions, the required surface finish might not attend the requirements.

\subsection{Grinding power and other analyses}

According to Tönshoff and Inasaki [19], the monitoring of power is commonly used in grinding processes. The main reason for that is its easy installation with no influence on the process and low cost, making it very used in the industrial environment to detect collision and to prevent machine overload.

Furthermore, the power signal offers a very reliable information regarding the energy consumption in the process, which is proportional to the amount of material removed by the abrasive tool.
From the graphs obtained for power in function of time, it was possible to calculate an average power value for each condition and plot the graph shown in Fig. 10:

It is possible to observe in Fig. 10 that the values of average power obtained were always smaller for the CBN GS wheel. This can be explained by the fact that the most friable wheel produces sharp new edges more frequently and efficiently, making the cutting easier and, consequently, the average power lower. It is interesting to observe that, although the wheel wear was more accentuated on the GS wheel, the effect of the higher friability prevailed and the average power measured was lower than the values obtained with the GL wheel.

With regard to the feed rate, the power generated using the CBN GS wheel varied more than that using the CBN GL wheel, indicating that the friability of the CBN GS wheel reduced the power required for cutting more effectively when the wheel is subjected to lower forces, since the constant creation of new cutting edges along with a low wheel wear facilitates the removal of material in milder conditions. Conversely, in more severe conditions, within the range analyzed, greater friability reduced the required power to a lesser extent.

The explanation for the observed phenomenon of less efficiency of the more friable wheel in the removal of material at more severe conditions is that, due to the more accentuated wear of this wheel as a result of the predominance of macrofracturing breakdown mode, the difference of depths of the abrasive grains from the wheel surface became also higher and the cutting became less homogeneous, causing the power required to increase considerably, which also reflected on the surface roughness results, as seen in Section 3.2. The CBN GL wheel, on the other hand, wore less as a result of the predominance of micro-fracturing breakdown mode and removed material more homogeneously, resulting in similar values of average power between the wheels on the most severe condition. In other words, the reduction of required cutting power due to

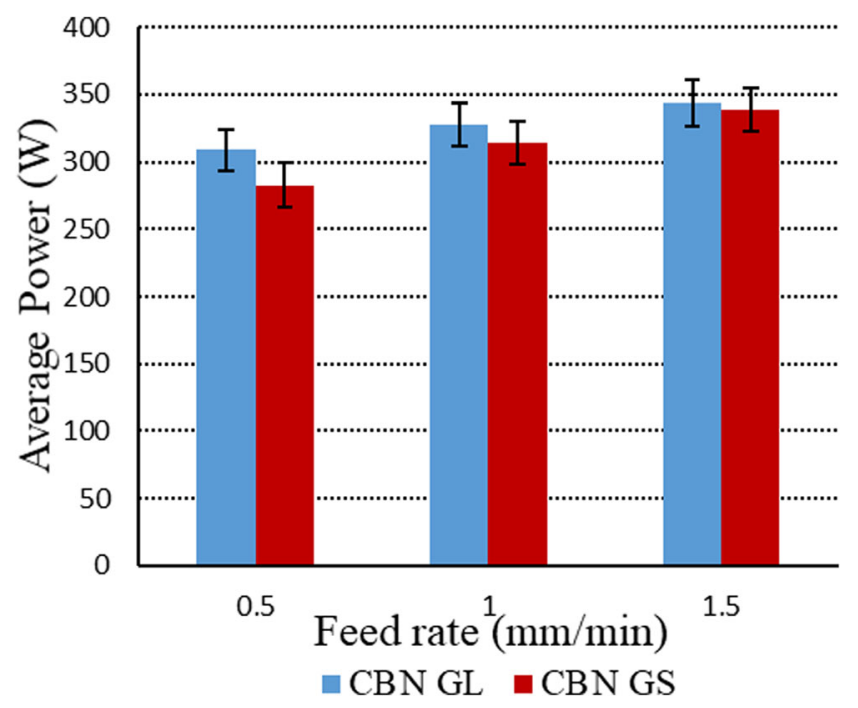

Fig. 10 Average grinding power in each experimental condition 
the higher friability of the CBN GS wheel (more frequent renovation of the cutting edges) was counterbalanced by the effect of the wheel wear.

Trend lines were created for the power values against feed rate for each grinding wheel, based on the average power data. The efficiency of each wheel at a given feed rate can be compared and estimated based on the power required, using the line equation provided by the software. Figure 13 shows the linearized curves for each wheel.

In Fig. 11, it can be seen that the slope of the linearized curve relative to the CBN GL grinding wheel is smaller than that of the CBN GS wheel, indicating that the increase in feed rate causes a higher variation in the average power required by the CBN GS wheel. Assuming that the linearized curves of the feed rates follow this slope up to the point they cross each other, it can be seen that they meet approximately at the point where the feed rate is $1.7 \mathrm{~mm} / \mathrm{s}$. Therefore, from this point on, the average grinding power of the CBN GS wheel will probably be higher than that of the CBN GL wheel. This also means that the CBN GL wheel is the best choice for more severe grinding conditions, while the CBN GS wheel removes material more easily at lower grinding forces.

It is also important to observe that the percentage increase of the feed rate did not result in an equivalent percentage increase of the average power. The increase of the feed rate from 0.5 to $1.5 \mathrm{~mm} / \mathrm{min}$ occasioned an increase of the average power in $11 \%$ on the GL wheel and $19 \%$ on the GS wheel. This means that the material removal was easier at higher feed rates on the analyzed range. This occurrence can be explained by the fact that the contribution of the sliding and plowing interactions of the abrasive grain with the workpiece in the chip formations are much less expressive when feed is high, resulting in easier cutting.

Based on the power vs. time curves, a routine was created in MATLAB to detect the maximum values of power in each

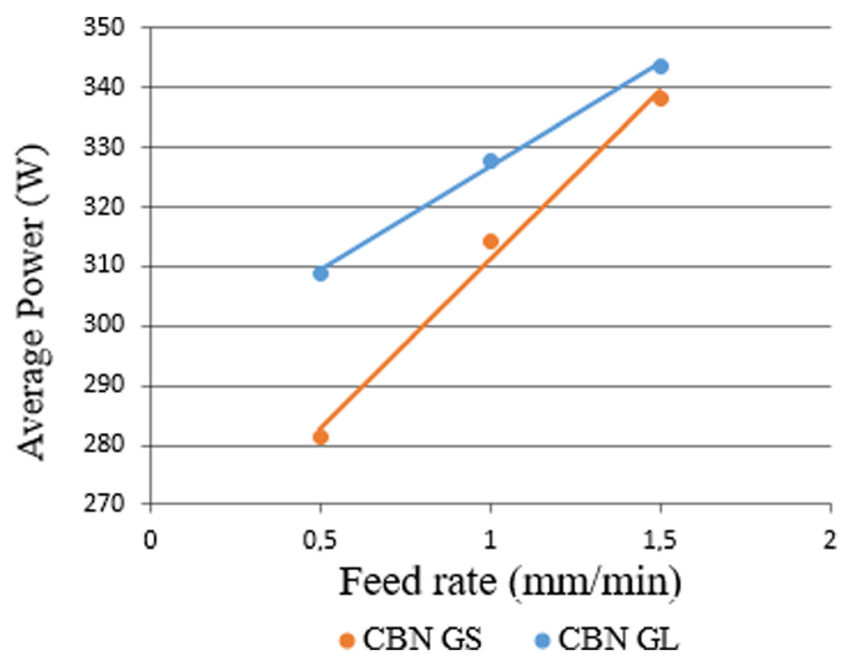

Fig. 11 Linearized curves of the average power per feed rate for each wheel

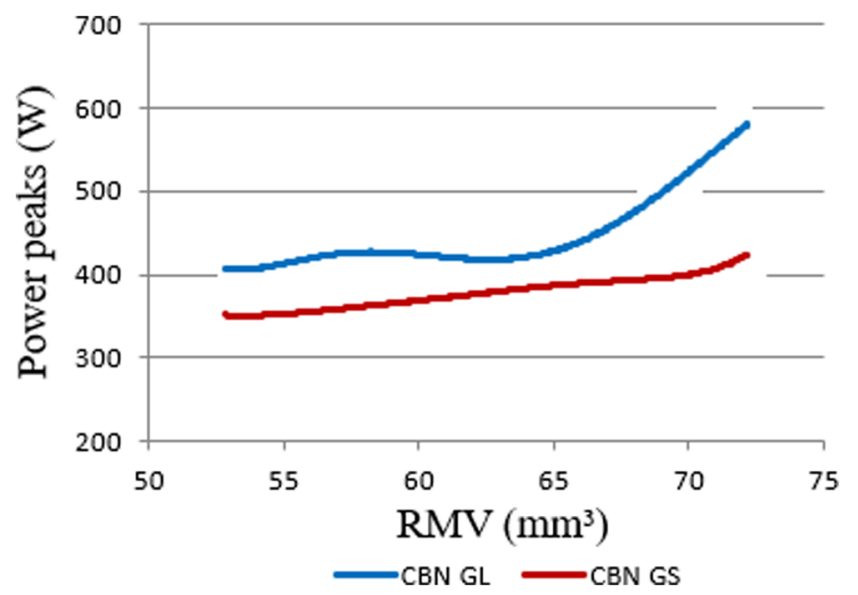

Fig. 12 Curves of the power peaks obtained for each cycle corresponding to a volume of material removed for feed rate of $0.5 \mathrm{~mm} / \mathrm{min}$

cycle and to relate each one to the respective value of material removed in the cycle. With this data, it was possible to plot a graph of dispersed points with 280 points regarding the power peak of each cycle and to relate it to the removed material volume per wheel pass (RMV) for each condition. A data file of each condition was then selected, and the behavior trend of the curves was obtained with polynomial curve fitting to better representation. The curves obtained for each condition are shown in the Figs. 12, 13, and 14, in which the $x$-axis indicates the removed material volume (in $\mathrm{mm}^{3}$ ) and the $y$-axis indicates the maximum power peaks for each grinding wheel according to the removed material volume.

Figure 12 sheds light on the behavior of each grinding wheel in terms of the power parameter within a range of RMV for each cycle at $0.5 \mathrm{~mm} / \mathrm{min}$, based on 280 points measured experimentally. To understand this figure, it is necessary to know that in the beginning of the process, the removal of material per wheel pass is higher (the workpiece diameter is higher). Consequently, the right side of the figure is related to the beginning of the operation (around $72 \mathrm{~mm}^{3}$

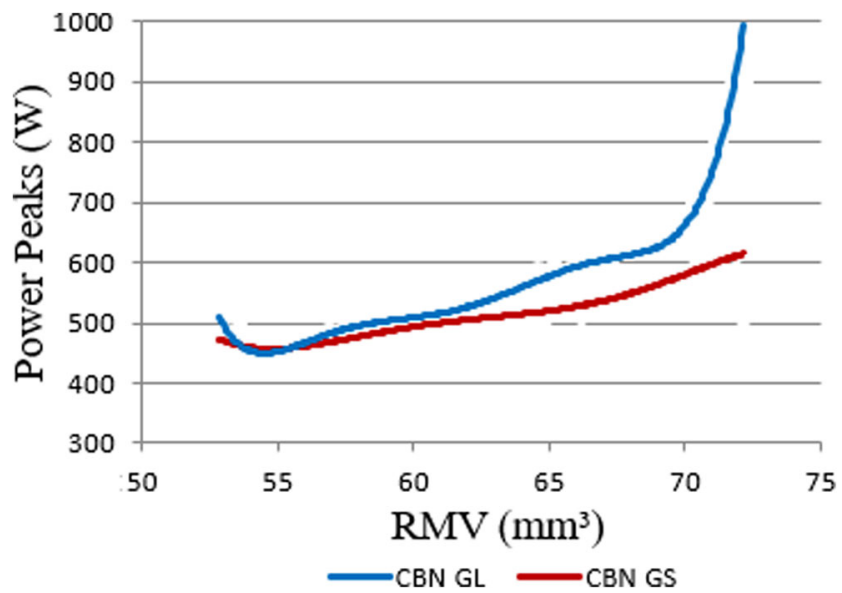

Fig. 13 Curves of the power peaks obtained for each cycle corresponding to a volume of material removed for feed rate of $1.0 \mathrm{~mm} / \mathrm{min}$ 


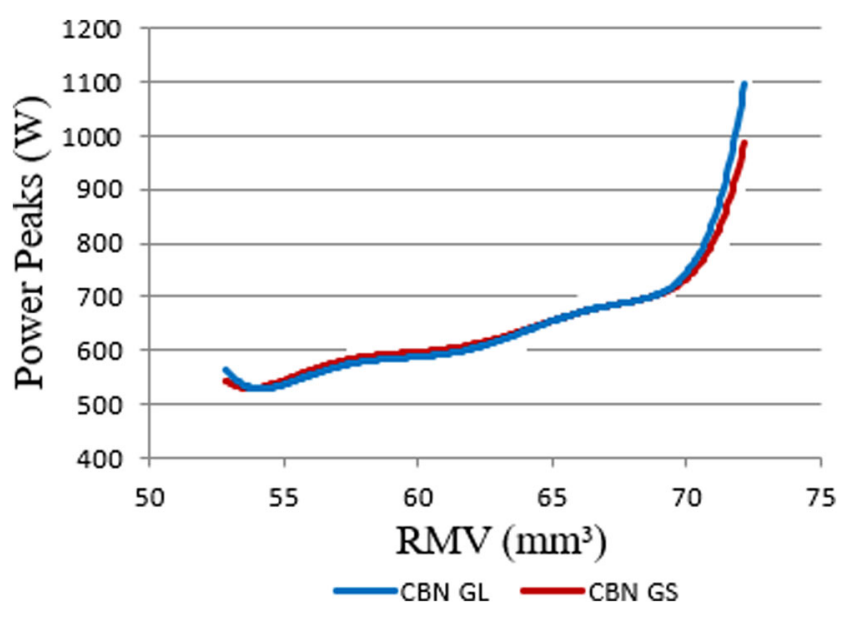

Fig. 14 Curves of the power peaks obtained for each cycle corresponding to a volume of material removed for $1.5 \mathrm{~mm} / \mathrm{min}$

per wheel pass) and the left side (around $52 \mathrm{~mm}^{3}$ per wheel pass) to the end. As the energy required to remove material is lower when the amount of removed material is also lower, the power required decreases as the process goes on. An analysis of the CBN GL curve allows to see that at approximately the middle of the process $\left(62 \mathrm{~mm}^{3}\right)$, the cutting power stopped to decrease, even though the removed material volume continued to get lower. This can be explained by the fact that at this point the less friable abrasive grains created less new cutting edges because the forces were not high enough and increasing the power needed to cut. These profiles also indicate that the CBN GS wheel is more efficient at this case because the power values are lower in the whole process and allow an easier cutting of the material, requiring a significantly lower amount of power for any point of RMV per cycle.

It can be seen in Fig. 13 that at higher values of removed material volume (which happens in the beginning of the process), CBN GL grinding wheel requires much more power to cut the material, but it is caused due to certain phenomena that are not the focus of this work. As the process goes on, the GS wheel, due to its higher friability, is renovating its edges more frequently and, consequently, is sharper than the GL wheel, which made the power consumed to be lower. However, when the removed material volume is approximately $60 \mathrm{~mm}^{3}$, the curves become considerably close and go on this way until the end. Therefore, in this condition, both wheels require the same power to do the cut, no matter the difference on the friability. This can be better explained by the fact that, although the CBN GS has highly friable abrasive grains, at certain point, the effects of the higher wear of this wheel result, as explained in the previous sections, in a grinding kinematics that increases the power required to cut and counterbalances the effect of the higher friability, making the power required to cut similar to the less friable wheel.

However, at a feed rate of $1.5 \mathrm{~mm} / \mathrm{min}$, which subjects both the grinding wheels to more severe cutting conditions, the curves are very similar. In other words, both wheels require a similar amount of power to remove material. The explanation for this phenomenon is that due to the accentuated wear of the CBN GS wheel in this condition, as seen in Section 3.1, the effect of higher difference of heights of abrasive grains from the wheel surface makes the cutting less homogeneous and the power required to cut is higher, counteracting the effect of the higher friability, which makes the curves of both wheels to be very similar. It is important to observe that, as the other output parameters analyzed indicate that the CBN GL wheel presents much better results at this feed rate, probably the use of this wheel should be advantageous in similar conditions.

\subsection{Microstructure and microhardness tests}

The process of grinding requires a significant amount of energy to perform material removal. During the process, that energy is transformed into heat, which is concentrated in the contact zone between the workpiece and the grinding wheel and a part of it is dissipated through the workpiece, sometimes causing several damages to it, such as burn, residual traction tensions, phase transformation, cracks, and reduction of resistance to fatigue. Aside from these factors, the thermal expansion of the workpiece during grinding contributes for dimensional and shape errors on the final product [20].

The samples related to each feed rate were analyzed under the optical microscope and no sort of burn or surface damage due to grinding was observed. Figure 15 shows the microstructure of the material on the ground surface under the most severe condition $(1.5 \mathrm{~mm} / \mathrm{min}$, with the CBN GL wheel).

As it could not be seen any visual alteration on Fig. 15 (ground surface obtained in the most severe condition-similar images were obtained for each ground workpiece) that could indicate some type of superficial or subsuperficial

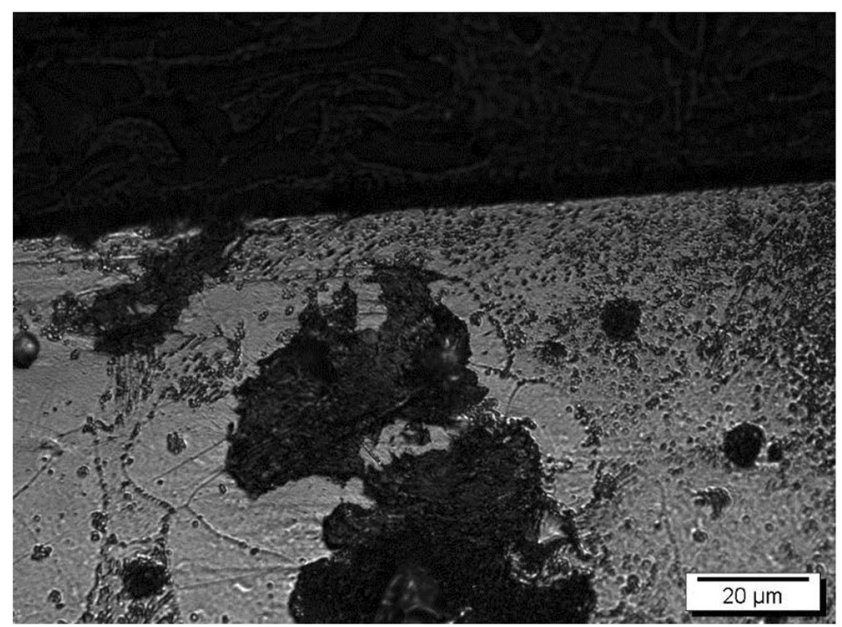

Fig. 15 Microstructure of the material on the ground surface under the most severe condition $(1.5 \mathrm{~mm} / \mathrm{min}$ CBN GL wheel). $\times 500$ 
damage, it can be concluded, together with the microhardness analysis, that the plastic deformations on the workpiece and the heat generated in the process were not high enough to cause microstructural alterations in the workpiece. As the surface of Fig. 15 was obtained using the condition which consumed the highest level of power (CBN GL wheel, at a feed rate of $1.5 \mathrm{~mm} / \mathrm{min}$ ), this conclusion can be extended to all the ground samples of the experiments.

To confirm the analysis done in the optical microscope, it is also important to perform an analysis of the microhardness values close to the ground surface and analyze if there was any kind of variation from the surface to the center of the workpiece. This is necessary because it is possible that the surface temperature, even not causing any phase transformation, may cause an extra tempering of the material and, consequently, to soften the surface and subsurface of the material. Therefore, it is important to analyze if variation in microhardness values on the surface occurred in comparison to points distant enough where the process could not affect.

If any difference from the microhardness of the surface to the microhardness of the subsurface is observed, it might indicate that a modification on the microstructure of the ground workpiece occurred.

Figure 16 shows the graph for the variation of microhardness of the samples in function of the distance from the ground surface.

A joint analysis of Figs. 15 and 16 shows that there was no type of thermal damage on the workpiece, since no pattern of microhardness variation from the surface to the subsurface was observed in any condition analyzed. The values obtained on the ground surface were sometimes higher and sometimes lower than the values obtained on the subsurface, but always randomly distributed, not presenting a uniform variation.

\section{Microhardness}
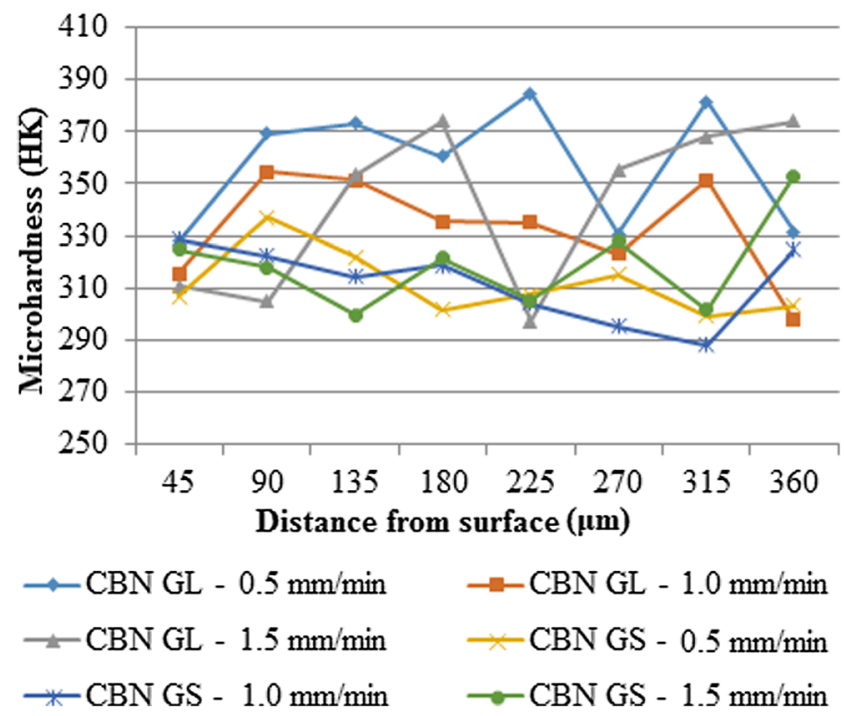

Fig. 16 Line graph showing the microhardness values obtained in function of the distance from the ground surface
Therefore, it can be concluded that the workpieces did not present any substantial metallurgical modifications caused by the process, which means that all the conditions were not severe enough to cause damages that could affect the workpiece quality.

\section{Conclusions}

Based on the results obtained in this work, it can be concluded, for the grinding process of nodular cast iron, that:

- Grinding using a less friable wheel (called CBN GL in this work) generated lower surface roughness of workpieces and lower wheel wear than grinding with a more friable wheel (called CBN GS in this work) due to the predominance of micro-fracturing and macro-fracturing breakdown modes, respectively. This difference of behavior impacted directly on the output parameters and the wheel wear also impacted on the surface roughness results;

- On the other hand, the less friable wheel consumed higher cutting power than the more friable one;

- As it was predicted by the literature, the increase of feed rate caused increase of surface roughness and wheel wear;

- The increase of feed rate also increased the consumption of power, but in a rate much smaller than the own feed growth, indicating that to cut using high feed is more energetically efficient than with low feed rate;

- No alteration in the workpiece microstructure and hardness was verified in the experiments, indicating that the wheels and cutting conditions used were not harmful for the workpiece properties.

Acknowledgments The authors thank the Group Saint Gobain Ceramic Materials/Surface Conditioning area for its donation of the CBN abrasive grains and for its support of this research, Nikkon Ferramentas de Corte Ltda for providing the grinding wheels and Quimatic Tapmatic Brazil for the donation of the cutting fluid used in this research.

Funding information This research received financial support from FAPESP and CNPq (Brazil).

Publisher's Note Springer Nature remains neutral with regard to jurisdictional claims in published maps and institutional affiliations.

\section{References}

1. Heisel U, Klocke F, Uhlmann E, Spur G (2014) Handbuch Spanen. Carl Hanser Verlag, Print ISBN: 978-3-446-42826-3. p. 14-17

2. Denkena B, Grove T, Bremer I, Behrens L (2016) Design of bronze-bonded grinding wheel properties. CIRP Ann Manuf Technol 65:333-336 
3. Rowe WB (2014) Principles of modern grinding technology. Elsevier, New York

4. Linke B (2016) Life cycle and sustainability of abrasive tools. Springer, Switzerland

5. Novoselov Y, Bratan S, Bogutsky V (2016) Analysis of relation between grinding wheel wear and abrasive grains wear. Procedia Eng 150:809-814

6. Jackson MJ (2007) Modelling of fracture wear in vitrified cBN grinding wheels. J Achiev Mater Manuf Eng 24:230-236

7. Jackson MJ, Davim JP (2011) Abrasive tools and bonding systems. Machining with abrasives. Springer Science, New York

8. Ding W, Zhu Y, Zhang L, Xu J, Fu Y, Liu W, Yang C (2015) Stress characteristics and fracture wear of brazed CBN grains in monolayer grinding wheels. Wear 332-333:800-809

9. Wu C, Li B, Liu Y, Liang SY (2017) Surface roughness modeling for grinding of silicon carbide ceramics considering co-existence of brittleness and ductility. Int J Mech Sci 133:167-177

10. Sosa AD, Echeverría MD (2015) Surface alterations produced in grinding of austempered ductile iron. Procedia Mater Sci 8:155161

11. Zeng D, Lu L, Zhang N, Gong Y, Zhang J (2017) Influence of a hybrid treatment consisting of fine particle bombardment and powder impact plating on the scuffing behavior of ductile cast iron. Wear 372-373:1-11

12. Iacoviello F, Cocco VD (2016) Influence of the graphite elements morphology on the fatigue crack propagation mechanisms in a ferritic ductile cast iron. Eng Fract Mech 167:248-258

13. Bouzakis KD, Bouzakis E, Kombogiannis S, Makrimallakis S, Skordaris G, Michailidis N, Charalampous P, Paraskevopoulou R,
M'Saoubi R, Aurich JC, Barthelma F, Biermann D, Denkena B, Dimitrov D, Engin S, Karpuschewski B, Klocke F, O" z T, Poulachon G, Rech J, Schulze V, Settineri L, Srivastava A, Wegener K, Uhlmann E, Zeman P (2014) Effect of cutting edge preparation of coated tools on their performance in milling various materials. CIRP J Manuf Sci Technol 7:264-273

14. Aurich JC, Effgen C, Kirsch B (2016) Cutting edge preparation with elastic bonded superabrasive grinding wheels. CIRP Ann Manuf Technol 65:329-332

15. Kuffa M, Kuster F, Wegener K (2016) Comparison of lubrication conditions for grinding of mild steel with electroplated $\mathrm{cBN}$ wheel. CIRP J Manuf Sci Technol 18:53-59. https://doi.org/10.1016/j. cirpj.2016.09.002

16. Taborga JDM (2002) Análise e Monitoramento da Retificação do Ferro Fundido Nodular com Rebolos de Nitreto de Boro Cúbico (CBN). Dissertação de Mestrado em Engenharia Mecânica, Universidade Federal de Santa Catarina, Florianópolis, 2002

17. Silva RS, Corrêa ECS, Brandão JR, Ávila RF (2013) Environmentally friendly manufacturing: behavior analysis of minimum quantity of lubricant - MQL in grinding process. $\mathrm{J}$ Clean Prod. https://doi.org/10.1016/j.jclepro.2013.01.033

18. Taborga ARM, Taborga JDM, Weingaertner WL (2003) Análise da Rugosidade Obtida na Retificação de Ferro Fundido Nodular Utilizando Rebolos de $\mathrm{SiC}$ e $\mathrm{Al}_{2} \mathrm{O}_{3}$. $2^{\circ}$ Congresso Brasileiro de Engenharia de Fabricação ( $\left.2^{\circ} \mathrm{COBEF}\right)$

19. Tönshoff HK, Inasaki I (2001) Sensors in manufacturing. WileyVCH publisher, Weinheim

20. Malkin S, Guo C (2008) Grinding technology: theory and application of machining with abrasives 